\title{
Relationships between nurse managers' work activities, nurses' job satisfaction, patient satisfaction, and medication errors at the unit level: A correlational study
}

Anu Nurmeksela ( $\square$ anu.nurmeksela@uef.fi )

University of Eastern Finland https://orcid.org/0000-0003-0474-0404

Santtu Mikkonen

University of Eastern Finland

Juha Kinnunen

Central Finland Central Hospital

Tarja Kvist

University of Eastern Finland

Research article

Keywords: job satisfaction, medication errors, nurses, nurse manager, patient satisfaction, hospital

Posted Date: December 1st, 2020

DOl: https://doi.org/10.21203/rs.3.rs-32156/v2

License: (c) (i) This work is licensed under a Creative Commons Attribution 4.0 International License. Read Full License

Version of Record: A version of this preprint was published at BMC Health Services Research on April 1st, 2021. See the published version at https://doi.org/10.1186/s12913-021-06288-5. 


\section{Abstract}

Background Nurse managers play a critical role in enhancing nursing and patient outcomes. A nurse manager's work, which can be described as a middle-manager at a health care organization, is complex and changes from day to day. Only a few studies have clarified how nurse managers divide their time across various work activities. This study aimed to describe the relationships between nurse managers' work activities, nurses' job satisfaction, patient satisfaction, and medication errors at the hospital unit level.

Methods A cross-sectional and correlational study design was used. The data were collected from nurse managers $(n=29)$, nursing staff $(n=306)$, and patients $(n=651)$ from 28 units across three Finnish acute care hospitals between April and November in year 2017. In addition, data concerning medication errors over one calendar year (2017) were acquired from the hospitals' incident reporting register. Analysis of covariance (ANCOVA) was used to estimate relationships between data from subareas of Nurse Managers' Work Content Questionnaire, Kuopio University Hospital Job Satisfaction Scale, and Revised Humane Caring Scale, along with medication errors reports. Significance level of $95 \%$ was used to estimate strength of covariances. Unstandardized coefficients (B) estimates were used to explain the relationship of variables.

Results Multiple relationships between nurse managers' work activities, nurses' job satisfaction, patient satisfaction, and medication errors were identified. Nurse managers' work activities had both positive and negative relationships on the other studied variables. The Requiring factors of work $(p<.001)$ subarea of nurses' job satisfaction, total patient satisfaction $(p<.001)$, and medication errors $(p<.001)$ were found to be the variables most significantly affected by other factors.

Conclusions The findings suggest that nurse managers should focus on improving nursing practices by managing and organizing nurses' work in a way that makes their employees feel supported, motivated and secure. Furthemore, nurse managers should adopt a leadership style that emphasizes safe and patientcentered care. The results also suggest that the administration of today's health care organizations should actively evaluate nurse managers' share of work activities to ensure that their daily work is in line with the organizational goals.

\section{Background}

Nurse managers' work is increasingly demanding in the current health care environment (1). Nurse managers largely influence nurses' job satisfaction $(2,3)$ and patient safety $(4,5)$, while motivated and engaged staff improve patient satisfaction $(6,7)$. Overall, nurse managers' work and behavior affect nursing outcomes in complex ways.

Only a limited number of studies have investigated how nurse managers divide their time across professional work activities (8-13), with a few studies focusing on how frequently nurse managers perform certain work activities (14-18). Nevertheless, previous literature has shown that nurse managers 
have various responsibilities and duties, ranging from staff recruitment and daily management to strategic planning and financial management (13). In recent years, nurse managers have become more involved in administrative work while their share of clinical work has diminished $(11,17,18)$. Recent studies have reported that nurse managers' daily work often consists of organizing, work scheduling and resource management $(13,19,20)$. Nurse managers can impact the quality of care $(21)$ by ensuring that their unit has sufficient staff and actively participates in the recruitment of competent staff (22-25).

Today, communication and collaboration represent a considerable part of nurse managers' work $(10,11,23,26-30)$. Cadmus and Wisniewska (2013) discovered that nurse managers most frequently perform rounds in their unit, guide staff on clinical matters, and have short meetings, or "huddles", with staff on a daily basis (15). Sveinsdottir et. al (2018) found that nurse managers' common daily activities also included "other domains", such as telephone calls, participating in planned meetings, and responding to e-mail. Furthermore, Chen et. al (2020) found that nurse managers frequently participate in information management on a daily basis. However, increased workloads among nurse managers have reduced the time they can share with nurses $(23,31-33)$. This presents a challenge, as nurse managers need to be visible and approachable, as well as give regular feedback to their staff $(26,34,35)$. As nurse managers are also tasked with promoting work protection $(20,32)$, work safety activities for staff $(33,36,37)$, and a healthy work environment (28), it is not unexpected that Chen et al. (2020) described nursing managers' daily work to also include patient management as well as supervising nursing quality and safety. Although it has been recognized that patient safety culture is influenced by hospital-level predictors, e.g., hospital size and staff education levels $(38,39)$, nurse managers nevertheless have an important role in patient safety at the unit level (Cummings et al., 2018).

Nevertheless, there is scarce research about how the activities that nurse managers perform are related to nursing outcomes. Instead, most of the available research covers how a nurse manager's leadership style and work behavior influence nursing outcomes. Multiple studies have identified a positive link between the relational leadership style and nurses' job satisfaction $(3,6,40)$, while other research has linked this leadership approach with patient satisfaction $(2,3,41)$. In addition, it is challenging for nurse managers to lead quality improvement in the complex everday environment of a health care organization (42). Recent studies have shown that leadership, managerial support and nurse-manager trust reduce medication errors and increase both patient safety culture and the quality of care $(5,6,43)$.

In summary, the current literature on nurse managers' leadership suggests that there are some relationships between hospital-level predictors and nursing outcomes, but the dynamics underlying these relationships may be highly complex. However, research regarding the relationships between nurse managers' work activities and nursing outcomes is not available. Due to the limited knoweldge base, this study aimed to describe the relationships between nurse managers' work activities, nurses' job satisfaction, patient satisfaction, and medication errors at the hospital unit level. The research question underlying the present study was: What are the relationships between nurse managers' work activities, nurses' job satisfaction, patient satisfaction, and medication errors? 


\section{Methods}

\section{Study design and participants}

This study applied a cross-sectional and correlational design. The research applied convenience sampling. A total of 104 nurse managers from three Finnish acute care hospitals were invited to participate in survey, with 61 answering the questionnaire. All of the nurses $(N=3225)$ and 50 patients $(N=3050)$ from each unit in which the participating nurse managers worked were invited to take part in the study. The inclusion criterion for respondents was that they were either a nurse manager at an inpatient wards or outpatient department, a registered nurse, midwife, practical nurse, or mental health and specialized nurses, or an adult patient who had been discharged from the hospital. The inclusion criterion for pooled units was that one nurse manager, three or more nurses, and three or more patients from the unit had answered the survey. Health care professionals working in operating rooms, intensive care units or paedatric units, as well as children patients, were excluded from the study. Register data describing the medication errors which had occurred over one year (2017) were acquired from the hospitals' incident reporting register. Data regarding nurse managers, nurses, patients and medication errors were pooled by every unit.

The first author visited each hospital and presented the study design plan at a nurse directors' and managers' meeting. Data were collected between April and November 2017 from nurse managers and nurses by e-mail and from patients by paper questionnaire. The questionnaires for nurse managers and nurses were sent to a contact person at each hospital, who then forwarded the email with the questionnaire link to nurse managers and nurses at the hospital. The paper questionnares for patients were distrubuted to each unit, and nurses were informed that they should give each patient the questionnaire (including a return envelope) when they are being discharged. A patient safety coordinator from each hospital delivered anonymous registered data of medication errors by e-mail or mail. All of the hospitals were public hospitals that offer specialized medical care. The included hospitals had between 390 to 440 beds and 2396 to 3748 employees. In addition, the hospitals had between 1285 and 1928 nursing staff (44).

\section{Measurements}

Data concerning the frequencies at which nurse managers perform various work activites were collected using an electronic questionnaire (Nurse Managers' Work Content Questionnaire, NMWCQ) (18). The NMWCQ was developed in 2016 to identify the content of nurse managers' work and which tasks they spend the most amount of time on. The questionnaire includes 87 items across 13 subscales, more specifically: Recruitment (5 items); Organizing (7 items); Work well-being (5 items); Work atmosphere (3 items); Communication (5 items); Clinical nursing (9 items); Development of the unit (12 items); Personnel development (8 items); Development of nursing (4 items); Financial management (7 items); Planning and evaluation of activities (6 items); Collaboration (10 items); and Development with collaborating partners (6 items). (Additional file 1). Nurse managers were asked to evaluate how frequently they perform various duties using a six-point Likert scale ( $1=$ daily; $2=$ weekly; $3=$ monthly; $4=2-4$ times a year; $5=$ annual; and $6=$ never). Principal component analysis was used to test the construct validity of the instrument. The 
development and preliminary results of the questionnaire were reported in an earlier study; as such, the data used in this study represent secondary data. Previous research reported Cronbach's alpha values between $0.554-0.890$ for the NMWCQ (18), while the Cronbach's alpha values ranged between 0,478-0,916 in this study (Table 2).

Nurses' job satisfaction was measured using the Kuopio University Hospital Job Satisfaction Scale (KUHJSS), with data collected via an electronic survey (45). The KUHJSS includes 15 background questions and seven subscales, namely, Leadership (7 items), Requiring factors of work (8 items), Motivating factors of the work (6 items), Working welfare (4 items), Participation in decision-making (4 items), Sense of community (4 items), and Working environment (4 items) (Additional file 2). The subscales include a total of 37 continuous scale questions, which respondents score from 0-10, i.e., totally disagree (0) - totally agree (10). Exploratory factor analysis was used to test the internal consistency of the instrument (45), while instrument validity and reliability were evaluated in several other studies. Cronbach's alpha values between 0.64-0.92 have previously been calculated for the KUHJSS $(45,46)$, while we calculated Cronbach's alpha values between $0.723-0.95$ for the data collected in the present study (Table 2).

Patients were asked to evaluate their satisfaction with care through a paper questionnaire that employed the Revised Humane Caring Scale (RHCS) $(47,48)$. This instrument includes seven background questions and seven subscales, namely, Professionalism of staff (17 items), Information and participation in own care (11 items), Responding to physical needs (4 items), Human resources (3 items), Pain and apprehension (4 items), Interdisciplinary collaboration (3 items), and Outcomes variables (4 items) (Additional file 3). These seven subscales include a total of 46 items, which respondents' grade from 0-10, i.e., totally disagree (0) - totally agree (10). Cronbach's alpha values between $0.775-0.946$ have been reported for the RHCS $(47,48)$, with values between $0.786-0.970$ calculated for the data collected in the present study (Table 2).

Data concerning medication errors during the year 2017 were acquired from the hospitals' incident reporting register (HaiPro). HaiPro is a national, web-based patient safety reporting system launched in 2007. Today, over 200 Finnish health- and social-care organisations report medication errors in HaiPro (49).

\section{Ethical considerations}

Ethics committee approval was obtained from the University of Eastern Finland. Approval was also requested, and received, from each of the three hospitals prior to data collection. Furthermore, the General Data Protection Regulation was followed throughout the research (50). Nurse managers, nurses and patients were informed of the voluntary nature of the study and that data would be anonymously analyzed. In addition, the registered data describing medication errors were anonymous.

\section{Data analysis}


Frequencies and percentage distributions were used to describe the demographic variables. Mean scores were calculated for the NMWCQ, KUHJSS and RHCS subscales while frequencies were used to describe medication errors. In addition, Cronbach's alpha values were calculated for the subscales of the NMWCQ, KUHJSS and RHCS to describe the internal consistency of questionnaires. Any missing data were excluded from the calculations. During data analysis, a Spearman's correlation matrix was first used to identify correlations between nurse managers' performed work activities, nurses' job satisfaction, and patient satisfaction. This analysis assesses the monotonic relationship - instead of the linear relationship between two variables (51). Subscales with correlation coefficients $\geq 0.3$ were included in the covariance analysis. ANCOVA is a statistical approach that is able to include both categorical and continuous predictors in a single model (51). This was necessary for our data as the studied predictors contain both types of variables. Hence, following the Spearman's correlation matrix, ANCOVA was used to evaluate the relationships between the NMWCQ, KUHJSS, and RHCS subscales and medication errors (51). The KUHJSS and RHCS subscales, along with medication errors, were applied as dependent variables and ANCOVA was used to test how these variables were affected by the subscales identified during the correlation analysis, as well as hospital size and the number of nurses per nurse manager. The subscales of NMWCQ, KUHJSS, RHCS, along with medication errors, were included as covariates. An inclusion criterion for the ANCOVA was that an item had $p \leq 0,1$. Unstandardized coefficients (B) estimates were used to explain the relationship between covariates and dependent variable. Furthermore, the original scale of the NMWCQ ( $1=$ daily, $2=$ weekly, $3=$ monthly, $4=2-4$ times a year, $5=$ annual, $6=$ never) was reversed to improve the interpretation of results, i.e. the reversed scale was: $6=$ daily; $5=$ weekly; $4=$ monthly; $3=2-4$ times a year; $2=$ annual; and $1=$ never. The data analyses were performed in SPSS for Windows (version 25.0, IBM Corporation, Armonk, NY).

\section{Results}

The ANCOVA yielded eight different models of patient satisfaction, six different models of nurses' job satisfaction and one model of medication errors. These models are presented below, along with descriptions of how the variables included in each are related to nurse managers' work activities. The analyses included data from 28 units, including responses from 29 nurse managers, 306 nurses, and 651 patients (Table 1). Each unit was generally represented by one nurse manager, with the exception of one unit which was represented by two nurse managers. The responding nurse managers, nurses and patients had average ages of 51,46 , and 57 years, respectively. Nurse managers were - on average - in charge of 35 nurses (range: 14-60). A total of 468 medication errors occurred across the 28 units during the one-year study period, which translates to an annual average of 18 medication errors per unit (range: 0-75).

\section{Table 1. Characteristics of nursing staff $(n=306)$ and patients $(n=651)$, described as number $(n)$ and percentage (\%)}

The mean score for nurse managers' work activities was 3.61 (on a scale of 1-6), with Clinical working being the least frequently performed activity (2.75) and Organizing being the most frequently performed activity (4.62). Nurses' total job satisfaction was 7.36 (on a scale of 0-10), with the Requiring factors of 
work and Motivating factors of the work subscales receiving the lowest (6.34) and highest (8.46) mean scores, respectively. The mean score for total patient satisfaction was 8.74 (on a scale of 0-10), with the Human resources and Professional practice subscales showing the lowest (8.51) and highest (9.16) scores, respectively (Table 2 ).

Table 2. Nurse managers' work activities $(n=29)$, nurses' job satisfaction $(n=306)$ and patient satisfaction ( $n=651$ ) presented according to subscale, and described using mean score, standard deviation (SD), and Cronbach's alpha

\section{Effects on Job satisfaction}

The results showed that six aspects of nurses' job satisfaction were affected by nurse managers' work, patient satisfaction and medication errors. The most significant effects were found for the Requiring factors of work subscale ( $p<$.001). For example, high ratings for both a nurse manager's Development of nursing duties and patient assessments of Cognition of physical needs were negatively related with this component of nurses' job satisfaction. The results revealed that nurses' assessments of general factors of their work were rather poor even though nurse managers were frequently involved in staff orientation and solving patient complaints. Furthemore, patient satisfaction with their psysical care was associated with poor ratings of work conditions (e.g. enough staff, satisfaction of working hours) among staff. However, patient views of Outcomes were positively associated with nurses' satisfaction with Requiring factors of work (Table 3).

There were inter-hospital differences in terms of nurses' perceptions of Working environment $(p=.002)$ (e.g. appropriate work facilities, work unit is safe and secure). Accordingly, nurses from hospital 1 scored this factor of job satisfaction higher than nurses from hospital 2, while nurses from hospital 3 gave this factor the lowest score. A small number of nurses $(n<40)$ per nurse manager was negatively related to nurses' perceptions of the Working environment. In other words, nurses working in small units were less satisfied with their working environment than nurses working in larger units. Furthermore, increased commitment towards Communication among nurse managers was negatively related with nurses' experiences of Working environment at the unit level (Table 3). A possible explanation is that Communication requires nurse managers to extensively prepare for, and manage, both meetings and huddles, which could decrese nurses' satisfaction with the units environment.

However, a small number of nurses per nurse manager $(n<40)$ was positively related with nurses' perceptions of Leadership ( $p=.047$ ). Hence, nurses in small units were more satisfied with their managers' leadership behavior than nurses working in larger units. In addition, patient ratings of Outcomes variables and the number of medication errors were both found to be positively associated with the Leadership aspect of nurses' job satisfaction. This means that patient satisfaction with treatment and outcomes translated to favorable assessment of leadership among nurses even if the unit had high medication errors rates. In contrast, high scores for nurse manager's Work well-being duties were negatively related with nurses' perceptions of Leadership. Both employee sick leaves and early support conversations are included in well-being duties. An increase in patient perceptions of Cognition of physical 
needs slightly decreased nurses' Working welfare $(p=.025)$. Accordingly, nurses who worked in an unit where patients needed more physical care evaluated their personal welfare poorly. Furthermore, increased commitment to Communication among nurse managers was negatively associated with nurses' ratings of Motivating factors of the work $(p=.050)$, as well as nurses' total job satisfaction $(p=.044)$. The amount of time which nurse managers spent in meetings and counsels was negatively related to nurses' motivation and overall work satisfaction. Patient ratings of Outcomes variables was positively correlated with total job satisfaction among nurses (Table 3).

\section{Table 3. The influences of nurse managers' work activities (NMWCQ), patient satisfaction (RHCS) and medication errors on nurses' job satisfaction subareas at the unit $(n=28)$ level}

\section{Effects on Patient satisfaction}

The analysis showed that eight subareas of patient satisfaction were affected by nurse managers' work activities, nurses' job satisfaction and medication errors. An increased focus on Work well-being among nurse managers, higher nurse ratings of Working welfare, and a greater number of medication errors were all found to decrease total patient satisfaction ( $p=.001$ ) (Table 4$)$. Thus, although a nurse manager's decision to allot more time to daily supportive duties may improve nurses' assessments of their work welfare, this management still may also increase medication errors, and therefore, decrease patient satisfaction. Furthermore, positive nurse assessments of a nurse manager's leadership were positively related to the Outcomes variables aspect of patient satisfaction $(p<.002)$. This means that patients were more satisfied with their care outcomes when nurses were satisfied with their managers' leadership behavior. In contrast, a high relative number of Medication errors in a unit was negatively related with the patient Outcomes variables subscale (Table 4).

The frequency at which nurse managers performed Work well-being duties and the number of medication errors were both found to decrease patient perceptions of Interdisciplinary collaboration $(p=.002)$. Nurse managers' work well-being duties include both promoting health at the workplace and supportive activities for staff. On the other hand, nurse managers' nursing development duties involve the orientation and training of staff in addition to handling patient complaints. The frequency at which nurse managers participated in Development of nursing duties and nurses' ratings of Requiring factors of work were both negatively related to patient perceptions of Cognition of physical needs $(p=.003)$. This could explain the patients' views of physical caring. It should be noted that nurses' asessesments of good work conditions, for example, the sufficiency of employees, may not reflect patients' experiences. Three factors decreased patient satisfaction with Professionalism practice $(p=.004)$, namely, a nurse manager's commitment to Organizing and Clinical nursing and nurses' perceptions of Leadership, i.e., units in which nurse managers frequently participated in Organizing and Clinical nursing, and in which nurses were confident with the managers' leadership, showed lower patient satisfaction relative to other wards (Table 4).-

Increased commitment to Communication among nurse managers was found to improve patient satisfaction with Pain and apprehension ( $p=.005)$. On the other hand, this component of patient satisfaction decreased with the frequency at which nurse managers participate in Development of nursing 
duties, nurses' perceptions of Working welfare and the number of medication errors (Table 4). Accordingly, an increase in patient complaints and medication errors increased the time that nurse managers spend investigating problems (i.e., Development of nursing). Moreover, we identified a seemingly paradoxical inverse relationship between nurses' work welfare and patient satisfaction with pain and apprehension.

Furthermore, the frequency at which nurse managers participated in Organizing duties and the number of medication errors were negatively related to patient assessments of Information and participation in own care $(p=.007)$. In addition, an increase in either a nurse manager's commitment to Financial management or the number of medication errors diminished patient satisfaction with Human resources $(p=.028)$ (Table 4). Daily organizing is largely focused on scheduling, which is also related to financial resources. In addition, poorly organized work could increase the amount of medication errors at a unit. Therefore, it is logical that these aspects would influence patients' perception of how much time nurses have to guide and inform patients, as well as the extent to which patients are involved in their own care.

\section{Table 4. The influences of nurse managers' work activities (NMWCQ), nurses' job satisfaction (KUHJSS) and medication errors on patient satisfaction (RHCS) subareas at the unit $(n=28)$ level}

\section{Effects on medication errors}

The results revealed that medication errors at the unit level are affected by nurse managers' work activities, patient satisfaction and the hospital as an organizational factor. However, only two of the tested variables were shown to significantly affect medication errors $(p<.001)$. The analysis revealed inter-hospital differences in medication error prevalence, with hospital 2 showing the highest prevalence, as well as significantly more medication errors than hospital 3 . Furthermore, the frequency at which nurse managers participated in Planning and evaluation of activities (e.g., process improvements) was found to be linked to an increase in medication errors. In contrast, patients' opinions of Outcomes variables were negatively related with medication errors. Consequently, units in which patients were satisfied with the outcomes of care also showed a lower number of medication errors rates than units in which patients were less satisfied with care (Table 5).

Table 5. The influence of hospital, nurse managers' work activities (NMWCQ), and patient satisfaction (RHCS) on medication errors at the unit $(n=28)$ level

To summarize, the performed analyses revealed several relationships between nurse managers' work activities, nurses' job satisfaction, patient satisfaction, and medication errors. Nurse managers' work activities had both positive and negative effects on the studied variables. The Requiring factors of work $(p<.001)$ aspect of nurses' job satisfaction, total patient satisfaction $(p<.001)$, and medication errors ( $p<$ .001 ) were found to be the studied variables that were most significantly effected by other factors.

\section{Discussion}

This study indicated how the frequency at which nurse managers perform various work activities, nurses' job satisfaction, patient satisfaction and medication errors are related on a unit level. Both negative and 
positive relationships were found. Three subareas of nurse managers' work (i.e. Work well-being, Development of nursing and Communication) were found to influence nurses' job satisfaction. It should be noted that even though the effects were minor, all of these relationships were negative (i.e. increasing nursing manager commitment to these classes of activities decreased nurses' job satisfaction). Furthermore, the frequencies describing how often nurses managers performed five classes of work activities (i.e. Organizing, Clinical nursing, Development of nursing, Financial management and Work wellbeing) negatively influenced patient satisfaction, while the frequency at which nurse managers participated in Communication had a positive impact on patient satisfaction. However, only one aspect of both nurse managers' work (Planning and evaluation of activities) and patient satisfaction (Outcomes variables), in addition to the specific hospital, significantly affected the incidence of medication errors at the unit level.

Job satisfaction

Concerning nurses' job satisfaction, Requiring factors of work was negatively affected by nurse managers' focus on Development of nursing and by patient satisfaction regarding Cognition of physical needs, while this aspect of job satisfaction was positively linked to patient views of Outcomes variables. A potential explanation is that a nurse manager's decision to allocate resources to nursing processes, along with the education and orientation of staff, would reduce the resources for bedside nursing, and therefore, may influence nurse staffing. According to several studies, scheduling and organizing are part of nurse managers' daily work responsibilities $(13,19,20)$.

Furthermore, patient satisfaction with Outcomes variables positively affected nurses' job satisfaction in terms of both Requiring factors of work and total job satisfaction. Recent research by De Simone et al. (2018) and Zaghini et al. (2020) provides support for these findings, i.e. both of these studies reported correlations between patient satisfaction and nurses' job satisfaction $(54,55)$. Nurses are motivated to provide high-quality care (48); as such, it is logical that patient satisfaction with the outcomes of care will improve nurses' job satisfaction.

The frequency at which nurse managers perform Communication tasks negatively affected nurses' total job satisfaction, along with the following aspects of nurses' job satisfaction: Motivating factors of the work; Working environment, and Leadership. The subarea of Communication includes preparing for and participating in meetings, managing unit meetings, and conversations with personnel. These findings were similar to the results reported by Kirchhoff \& Karlsson (2019), more specifically, nurse managers who frequently engage in meetings with management, such as networking with other managers and involvement in management-level projects, were less visible in the organizational unit (31). Several studies have reported that nurse managers need to be visible, accessible, and provide regular feedback to their staff $(26,34,35)$. This could be the reason why nurses were less motivated and satisfied when their managers were highly focused on communication tasks. An alternative explanation is that a large proportion of nurses felt that multiple staff meetings were unnecessary and unmeaningful. These results suggest that nurses managers should focus on their communication skills, e.g. discussing difficult 
questions, listening to different opinions, delivering construtive feedback, and disseminating up-to-date information, rather than the time they spend on communication tasks $(27,56)$.

When rating the Working environment aspect of job satisfaction, nurses evaluate whether they are provided appropriate work facilities that are safe and secure. Fang et al. (2018) found that over one-third of nurses thought that they work with unsafe equipment and did not feel adequately supported, while nearly half of nurses felt unsafe in the workplace. However, additional research found that nurses believe that nurse managers are able to change the work systems and equipment to promote nurse safety (57). In addition, Agnew et al. (2014) found that a nurse manager's behavior regarding the monitoring (e.g. auditing) and recognizing (e.g. rewarding) of safety issues influences the compliance of staff. Another study reported that the hospital and number of nurses influence both nurses' perceptions of the work environment and/or nurse managers' leadership abilities. Consequently, nurses from units with less staff were more satisfied with their managers' leadership behavior than nurses from units with more staff. On the other hand, units with less nurses were more characterized by lower ratings of their work environment in comparison to units with more nursing staff. The nursing practice environment has been found to impact staff perceptions' of staffing and resource adequacy. However, staffing is not the sole reason for dissatisfaction among nurses. For example, dissatisfaction can also be the result of poor leadership and management, lack of lifelong learning opportunities, poor nurse empowerment, an insecure work environment, and strained nurse-physician relationships (58). In addition, other organizational factors such as environment or culture, organizational support, and staffing adequacy - can contribute to nurses' job satisfaction $(40,59)$.

Patient satisfaction

The performed analyses revealed that total patient satisfaction is significantly influenced by nurse managers' Work well-being, nurses' Working welfare and medication errors. This means that patients are satisfied when nurse managers treat staff members equally, are interested in staff well-being, provide staff feedback with the aim of developing work, and are interested in work results and outcomes (19). Hence, nurse managers influence patient satisfaction in various ways.

Nurses' satisfaction with Leadership had a positive impact on patients' Outcomes variables, which describes the goals of treatment and satisfaction with outcomes and care, while the number of medication errors had negative influence on this aspect of patient satisfaction. For example, an increase in nurses' perceptions of their nurse managers' leadership behavior could be expected to improve patient outcomes. Several previous studies have also confirmed that nurse managers' leadership is related to nurses' job satisfaction $(40,60,61)$. Furthermore, additional studies have linked nurses' job satisfaction with patient outcomes (53) and patient satisfaction $(6,59)$.

An interesting finding of this study was that the frequency at which nurse managers performed numerous tasks had a negative impact on different components of patient satisfaction. For example, a nurse manager's decision to dedicate more time to Organizing, Work well-being, Work atmosphere, Financial management, Clinical nursing or Development of nursing care was found to decrease at least one subscale

Page $11 / 24$ 
of patient satisfaction. However, it should be noted that most of these observed decreases were rather slight. In contrast, a nurse manager's focus on Communication improved patient evaluations of Pain and apprehension. It is also important to note that the frequency at which a nurse manager performs a certain task does not necessarily denote an improvement in the quality of work. For example, several recent studies have emphasized that nurse managers are overwhelmed by their workloads. According to Steege et. al. (2017), fatigue among nurse managers decreases the quality of their work, and can impact decisionmaking (62). On the other hand, research by Labrague et al. (2018) suggests that - in some cases - more control over a job, along with a higher extent of responsibility, lead to less occupational stress. For these reasons, it is important to review and evaluate how nurse managers' work activities are scheduled, and concentrate to developing collaboration with colleagues and supervisors.

\section{Medication errors}

Several of the tested variables significantly influenced the incidence of medication errors. These included the frequency at which nurse managers performed certain tasks, patient satisfaction, and the studied hospital, each of which affected the incidence of medication errors at the unit level. There were large interhospital differences, as hospitals 1 and 2 had nearly 10 and 15 times more medication errors, respectively, than hospital 3. Another important finding was that the frequency at which nurse managers participated in Planning and evaluating activities significantly increased the amount of medication errors at a unit. Nurse managers are responsible for the fluency of nursing processess and ensuring that all staff members understand the organizational goals. Consequently, they connect the clinical environment with the organizational culture. Accordingly, units with strong patient safety culture are characterized by organizational learning, continuous improvement, nonpunitive responses to errors, as well as feedback and open communication, and therefore have a lower incidence of adverse events than units that do not perform as strongly across these safety culture aspects. Furthermore, these environments include an atmosphere in which employees feel safe to report medication errors, discuss them, and learn from previous mistakes. $(3,63)$. Patient evaluations of their care and treatment were negatively related with medication errors, i.e., units with patients who were satisfied with their care show less medication errors that units in which patients are not as satisfied with their care.

In summary, the increased share of administrative duties alloted to nurse managers means that they are rarely in the vicinity of patients and nurses. Although nurse managers are responsible for organizing their units, it is equally important that they find sufficient time to support and motivate their staff. However, it is important to note that nurse managers can indirectly improve patient care and outcomes by fostering a safe work environment in their unit.

\section{Strengths \& Limitations}

The main limitation of this study was that only three hospitals were involed in the study, from which only 28 units met the inclusion criteria. Accordingly, the study include a small sample of nurse managers because there is usually one (rarely two or more) nurse managers per unit. The small amount of units limited the choice of an appropriate analytic method. Therefore, structural equation modelling was 
excluded, with analysis of covariance chosen to investigate relationships between the variables (51). Nevertheless, the fact that 305 nurses and 651 patients participated in the study could be considered a strength when considering that the power analysis specified that 344 nurses and 342 patients should be included to obtain accurate descriptions of the interactions between variables. In addition, we only studied patient satisfaction and nurses' job satisfaction at the unit level. However, we did examine how the number of nurses per nurse manager affects patient satisfaction, nurses' job satisfaction, and medication errors. Hence, the presented results provide information about possible interactions between nurse managers' work content, nurses' job satisfaction, patient satisfaction, and medication errors.

The NMWCQ is a new instrument and, as such, needs to be tested more. It is also important to note that all of the questionnaires (NMWCQ, KUHJSS, and RHCS) are based on self-assessment, which can introduce a certain degree of bias as respondents tend to overestimate their own skills (64). However, several studies have reported that the KUHJSS and RHCS are reliable and valid instruments. Medication error data from the HaiPro register are based on nurses' initiative to report medication errors. Therefore, it is impossible to know whether every medication error has been reported. However, it should be noted that HaiPro is the first adverse event reporting system that was introduced in Finland and is now widely used. To gain a representative picture of medication errors, we decided to collect medication error data over one year, whereas other data were collected over a time period of approximately one month.

Although, the study has been conducted in Finland, the results can be utilized - to a certain degree - in the evaluation and development of nurse managers' work on an international level. In the future, it would be interesting to examine whether the hours each registered nurse spent per patient affected patient satisfaction or medication errors. In addition, it would be worthwhile to further develop the NMWCQ and apply it in studies which include far larger samples than what was analyzed in the current study. This means that future studies should involve more hospitals and units than the three investigated in this study. This would allow researchers to use different statistical methods - such as structural equation modeling to assess the relationships between nurse managers' work content, nurses' job satisfaction, patient satisfaction and medication errors. Furthermore, it is important to state that the presented results could be verified by applying different measures of nurse managers' workload and daily tasks.

\section{Conclusions}

The present study identified several relationships between nurse managers' work activities, nurses' job satisfaction, patient satisfaction, and medication errors. In addition, organizational factors - such as the number of nurses per nurse manager and hospital - also influenced nurses' job satisfaction and medication errors. The findings suggest that nurse managers should focus on improving nursing practices by managing and organizing nurses' work in a way that makes their employees feel supported, motivated and secure. Furthermore, nurses managers should lead in a way that emphasizes safe and patientcentered care. It would be advisable that the administration at health care organizations critically evaluate nurse managers' work activities to determine whether the current division of tasks will enable them to meet organizational goals. If not, the organization should proactively develop the work of nurse managers, 
preferably through collaboration with colleagues, to match what is required in the modern health care organization.

\section{Abbreviations}

Analysis of covariance (ANCOVA), Nurse Managers' Work Content Questionnaire (NMWCQ), Kuopio University Hospital Job Satisfaction Scale (KUHJSS), Revised Humane Caring Scale (RHCS), number of participants (n), Standard Deviation (SD), Cronbach's Alpha (a), Significance ( $p)$, Unstandardized coefficients (B)

\section{Declarations}

\section{Ethics approval and consent to participate}

The Committee of Research Ethics of University of Eastern Finland (Decision Date: 07.02.2017, No: 6/2017) reviewed the ethical aspects of the research project and issued a statement regarding its ethical acceptability. We conducted three anonymous, self-administered questionnaires, and considered answering the questionnaire as consent to participate in the study.

\section{Consent for publication}

Not applicable.

\section{Availability of data and materials}

All data supporting our findings were presented within the manuscript.

\section{Competing interests}

The authors declare that they have no competing interests.

\section{Funding}

This study was supported by the Finnish Nurses Association and The Nurses Training Foundation. SM was supported by The Academy of Finland Competitive funding to strengthen university research profiles (PROFI) for the University of Eastern Finland (grant no. 325022). The funding institutions did not have any role in the design of this study, the collection or interpretation of the data, or the preparation of the manuscript.

\section{Author's contributions}

AN and TK acquired the data and designed the study. AN and SM performed the statistical analysis. AN prepared the draft of the manuscript. AN and TK made major contributions to the conception and design of the study as well as data acquisition, analysis, and interpretation. TK, SM, and JK also revised this manuscript. All authors read and approved the final manuscript. 


\section{Acknowledgements}

We would like to thank the hospitals and their contact persons for cooperation, along with the nurse managers, nurses, and patients who contributed to the study by completing the questionnaires.

\section{Author details}

1 University of Eastern Finland, Faculty of Health Sciences, Department of Nursing Sciences, Kuopio, Finland

2 University of Eastern Finland, Department of Applied Physics and Department of Environmental and Biological Sciences, Kuopio, Finland

3 Central Finland Central Hospital

4 University of Eastern Finland, Faculty of Health Sciences, Department of Nursing Sciences, Kuopio, Finland

\section{References}

1. Udod SA, Cummings G, Care WD, Jenkins M. Impact of Role Stressors on the Health of Nurse Managers. JONA J Nurs Adm [Internet]. 2017;47(3):159-64. Available from: http://insights.ovid.com/crossref?an=00005110-201703000-00007

2. McCay R, Lyles AA, Larkey L. Nurse Leadership Style, Nurse Satisfaction, and Patient Satisfaction: A Systematic Review. J Nurs Care Qual. 2018;33(4):361-7.

3. Hughes V. Nurse leader impact: A review. Nurs Manage. 2019;50(4):42-9.

4. Merrill KC. Leadership Style and Patient Safety: Implications for Nurse Managers. J Nurs Adm. 2015;45(6):319-24.

5. Lotfi Z, Atashzadeh-Shoorideh F, Mohtashami J, Nasiri M. Relationship between ethical leadership and organisational commitment of nurses with perception of patient safety culture. J Nurs Manag. 2018;26(6):726-34.

6. Boamah SA, Spence Laschinger HK, Wong C, Clarke S. Effect of transformational leadership on job satisfaction and patient safety outcomes. Nurs Outlook [Internet]. 2018;66(2):180-9. Available from: https://doi.org/10.1016/j.outlook.2017.10.004

7. Doucette JN. Nursing Management partners with ANCC's Pathway to Excellence® Program. Nurs Manage [Internet]. 2018 Apr;49(4):13-5. Available from: http://search.ebscohost.com/login.aspx? direct $=$ true $\& \mathrm{db}=$ cin $20 \& A \mathrm{~N}=128582799 \&$ site $=$ ehost-live

8. Locke R, Leach C, Kitsell F, Griffith J. The impact on the workload of the Ward Manager with the introduction of administrative assistants. J Nurs Manag. 2011;19(2):177-85.

9. Buchanan DA, Parry E, Gascoigne C, Moore C. Are healthcare middle management jobs extreme jobs? J Heal Organ Manag. 2013;27(5):646-64. 
10. Ericsson U, Augustinsson S. The role of first line managers in healthcare organisations - a qualitative study on the work life experience of ward managers. J Res Nurs. 2015;20(4):280-95.

11. Bjerregård Madsen J, Kaila A, Vehviläinen-Julkunen $\mathrm{K}$, Miettinen M. Time allocation and temporal focus in nursing management: An integrative review. J Nurs Manag. 2016;24(8):983-93.

12. Kristiansen M, Westeren KI, Obstfelder A, Lotherington AT. Coping with increased managerial tasks: tensions and dilemmas in nursing leadership. J Res Nurs. 2016;21(7):492-502.

13. Warshawsky N, Cramer E. Describing Nurse Manager Role Preparation and Competency: Findings from a National Study. J Nurs Adm. 2019;49(5):249-55.

14. Baker S, Marshburn DM, Crickmore KD, Rose SB, Dutton K, Hudson PC. What do you do? Perceptions of nurse manager responsibilities. Nurs Manag [Internet]. 2012;43(12):24-9. Available from:

http://content.wkhealth.com/linkback/openurl?sid=WKPTLP:landingpage\&an=00006247-20121200000007

15. Cadmus E, Wisniewska EK. Measuring first-line nurse manager work: Instrument: development and testing. J Nurs Adm. 2013;43(12):673-9.

16. Chen W, Rn JC, Rn JH, Junqiang A, Rn Z, Zhang J, et al. The professional activities of nurse managers in Chinese hospitals: A cross-sectional survey in hunan province. J Nurs Manag. 2020;00(March):1-9.

17. Sveinsdóttir H, Blöndal K, Jónsdóttir HH, Bragadóttir H. The content of nurse unit managers' work: a descriptive study using daily activity diaries. Scand J Caring Sci. 2018;32(2):861-70.

18. Nurmeksela A, Kinnunen J, Kvist T. Nurse managers' work content: Development of the questionnaire and results of the pilot study. Scand J Caring Sci. 2019;(8):3-6.

19. Morsiani G, Bagnasco A, Sasso L. How staff nurses perceive the impact of nurse managers' leadership style in terms of job satisfaction: a mixed method study. J Nurs Manag. 2017;25(2):11928.

20. Wong CA, Elliott-Miller P, Laschinger $H$, Cuddihy $M$, Meyer RM, Keatings $M$, et al. Examining the relationships between span of control and manager job and unit performance outcomes. J Nurs Manag. 2015;23(2):156-68.

21. Squires A, Jylhä V, Jun J, Ensio A, Kinnunen J. A scoping review of nursing workforce planning and forecasting research. J Nurs Manag. 2017;25(8):587-96.

22. Weaver $\mathrm{SH}$, Lindgren T. Administrative supervisors a qualitative exploration of their perceived role. Nurs Adm Q. 2016;40(2):164-72.

23. Rankin J, Mcguire C, Matthews L, Russell M, Ray D, on behalf of the Leading Better Care Research. Facilitators and barriers to the increased supervisory role of senior charge nurses: A qualitative study. J Nurs Manag. 2016;24(3):366-75.

24. Gunawan J, Aungsuroch Y, Fisher ML. Competence-based human resource management in nursing: $A$ literature review. Nurs Forum. 2019;54(1):91-101.

25. Aiken LH, Sloane D, Griffiths P, Rafferty AM, Bruyneel L, Mchugh M, et al. Nursing skill mix in European hospitals: cross-sectional study of the association with mortality , patient ratings, and quality of care. 2017;26:559-68. 
26. Sveinsdóttir H, Ragnarsdóttir ED, Blöndal K. Praise matters: The influence of nurse unit managers' praise on nurses' practice, work environment and job satisfaction: A questionnaire study. J Adv Nurs. 2016;72(3):558-68.

27. Rouse RA, Al-Maqbali M. Identifying nurse managers' essential communication skills: An analysis of nurses' perceptions in Oman. J Nurs Manag. 2014;22(2):192-200.

28. Shirey MR. Leadership practices for healthy work environments. Nurs Manage. 2017:4:9-15.

29. Weaver SH, Hessels AJ, Paliwal M, Wurmser TA. Administrative Supervisors and Nursing Unit-Based Managers: Collaboration and Job Satisfaction. Nurs Econ. 2019;37(2):67-76.

30. Yen M, Trede F, Patterson C. Learning in the workplace: the role of Nurse Managers. Aust Heal Rev. 2016;40(3):286-91.

31. Kirchhoff JW, Karlsson JC. Alternative careers at the first level of management: First-line nurse managers' responses to role conflict. Leadersh Heal Serv. 2019;32(3):405-18.

32. Townsend $\mathrm{K}$, Wilkinson A, Kellner A. Opening the black box in nursing work and management practice: The role of ward managers. J Nurs Manag. 2015;23(2):211-20.

33. Warshawsky N, PhD RN, Rayens M, Lake S, Havens D, Sullivan PhD RN. The Nurse Manager Practice Environment Scale: Development and Psychometric Testing. J Nurs Adm [Internet]. 2013;43(5):250-7. Available from: http://ovidsp.ovid.com/ovidweb.cgi?

$\mathrm{T}=\mathrm{JS} \& \mathrm{PAGE}=\mathrm{reference} \& \mathrm{D}=\mathrm{ovftn} \& \mathrm{NEWS}=\mathrm{N} \& A \mathrm{~N}=00005110-201305000-00004$

34. Omery A, Crawford CL, Dechairo-Marino A, Quaye BS, Finkelstein J. Re-examining nurse manager span of control with a 21st-century lens. Nurs Adm Q. 2019;43(3):230-45.

35. Stevanin S, Voutilainen A, Bressan V, Vehviläinen-Julkunen K, Rosolen V, Kvist T. Nurses' Generational Differences Related to Workplace and Leadership in Two European Countries. West J Nurs Res. 2020;42(1):14-23.

36. Pegram AM, Grainger M, Sigsworth J, While AE. Strengthening the role of the ward manager: A review of the literature. J Nurs Manag. 2014;22(6):685-96.

37. Udod SA, Care WD. "Walking a tight rope": An investigation of nurse managers' work stressors and coping experiences. J Res Nurs. 2012;18(1):67-79.

38. Mazurenko O, Collum T, Ferdinand A, Menachemi N. Predictors of Hospital Patient Satisfaction as Measured by HCAHPS: A Systematic Review. J Healthc Manag. 2017;62(4):272-83.

39. Mcfarland DC, Shen MJ, Parker P, Meyerson S. Does Hospital Size Affect Patient Satisfaction? Qual Manag Healthc. 2017;26(4):205-9.

40. Cummings GG, Tate K, Lee S, Wong CA, Paananen T, Micaroni SPM, et al. Leadership styles and outcome patterns for the nursing workforce and work environment: A systematic review. Int J Nurs Stud [Internet]. 2018;85(April):19-60. Available from: https://doi.org/10.1016/j.jjnurstu.2018.04.016

41. Alloubani A, Akhu-Zaheya L, Abdelhafiz IM, Almatari M. Leadership styles' influence on the quality of nursing care. Int J Health Care Qual Assur. 2019;32(6):1022-33.

42. Sjølie BM, Hartviksen TA, Bondas T. "navigation to prioritizing the patient" - First-line nurse managers' experiences of participating in a quality improvement collaborative. BMC Health Serv Res. 
2020;20(1):1-13.

43. Kim MS, Seok JH, Kim BM. Mediating role of the perceived benefits of using a medication safety system in the relationship between transformational leadership and the medication-error management climate. J Res Nurs. 2019;

44. Association of Finnish Local and Regional Authorities. Hospitals and Hospital Districts January to December 2017. Summary of demand, production and economy [Internet]. 2018 [cited 2018 Jul 4]. p. 47. Available from: https://www.kuntaliitto.fi/asiantuntijapalvelut/sosiaali-jaterveysasiat/sairaanhoitopiirien-osavuosi-ja-vuosikatsaukset

45. Kvist T, Mäntynen R, Partanen P, Turunen $H$, Miettinen $M$, Vehviläinen-Julkunen $K$. The Job Satisfaction of Finnish Nursing Staff: The Development of a Job Satisfaction Scale and Survey Results. Nurs Res Pract [Internet]. 2012;2012:1-11. Available from: http://www.hindawi.com/journals/nrp/2012/210509/

46. Ylitörmänen $\mathrm{T}$, Turunen $\mathrm{H}$, Kvist $\mathrm{T}$. Job satisfaction among registered nurses in two Scandinavian acute care hospitals. J Nurs Manag [Internet]. 2018;26:888-97. Available from: http://doi.wiley.com/10.1111/jonm.12620

47. Kvist T, Mäntynen R, Turunen $H$, Partanen P, Miettinen M, Wolf GA, et al. How magnetic are Finnish hospitals measured by transformational leadership and empirical quality outcomes? J Nurs Manag. 2013;21(1):152-64.

48. Kvist T, Voutilainen A, Mäntynen R, Vehviläinen-Julkunen K. The relationship between patients' perceptions of care quality and three factors: Nursing staff job satisfaction, organizational characteristics and patient age. BMC Health Serv Res. 2014;14(1):1-10.

49. Awanic Ltd. Reporting System for Safety Incidents in Health Care Organizations [Internet]. 2018. Available from: http://awanic.com/haipro/eng/

50. European Commission. General Data Protection Regulation (GDPR). Brussels, Belgium: European Commission. [Internet]. 2016. Available from: https://gdpr-info.eu/

51. Tabachnick BG, Fidell LS. Using multivariate statistics. 6th ed. Boston, MA: Pearson Education; 2014. $983 \mathrm{p}$.

52. Karlsson AC, Gunningberg L, Bäckström J, Pöder U. Registered nurses' perspectives of work satisfaction, patient safety and intention to stay - A double-edged sword. J Nurs Manag. 2019;27(7):1359-65.

53. Gillet N, Fouquereau E, Coillot H, Cougot B, Moret L, Dupont S, et al. The effects of work factors on nurses' job satisfaction, quality of care and turnover intentions in oncology. J Adv Nurs. 2018;74(5):1208-19.

54. Zaghini F, Fiorini J, Piredda M, Fida R, Sili A. The relationship between nurse managers' leadership style and patients' perception of the quality of the care provided by nurses: Cross sectional survey. Int J Nurs Stud. 2020;101.

55. De Simone S, Planta A, Cicotto G. The role of job satisfaction, work engagement, self-efficacy and agentic capacities on nurses ' turnover intention and patient satisfaction. Appl Nurs Res [Internet]. 
2018;39:130-40. Available from: https://doi.org/10.1016/j.apnr.2017.11.004

56. Henriksen J. An alternative approach to nurse manager leadership. Nurs Manage. 2016;47(1):53-5.

57. Fang Y, McDonald T. Management capacity to promote nurse workplace health and safety. J Nurs Manag. 2018;26(3):288-94.

58. Shimp KM. Systematic review of turnover/retention and staff perception of staffing and resource adequacy related to staffing. Nurs Econ. 2017;35(5).

59. Copanitsanou P, Fotos N, Brokalaki H. Effects of work environment on patient and nurse outcomes. $\mathrm{Br}$ J Nurs [Internet]. 2017;26(3):172-6. Available from: http://www.magonlinelibrary.com/doi/10.12968/bjon.2017.26.3.172

60. Lu H, Zhao Y, While A. Job satisfaction among hospital nurses: A literature review. Int J Nurs Stud [Internet]. 2019;94:21-31. Available from: https://doi.org/10.1016/j.ijnurstu.2019.01.011

61. Feather R. Tools assessing nurse manager behaviours and RN job satisfaction: A review of the literature. J Nurs Manag. 2015;23(6):726-35.

62. Steege LM, Pinekenstein BJ, Arsenault Knudsen É, Rainbow JG. Exploring nurse leader fatigue: a mixed methods study. J Nurs Manag. 2017;25(4):276-86.

63. Wong CA, Cummings GG, Ducharme $L$. The relationship between nursing leadership and patient outcomes: A systematic review update. J Nurs Manag. 2013;21(5):709-24.

64. Thoma C. Under-versus overconfidence: an experiment on how others perceive a biased selfassessment. Exp Econ [Internet]. 2016;19(1):218-39. Available from: http://dx.doi.org/10.1007/s10683-015-9435-2

\section{Tables}

Table 1. Characteristics of nursing staff $(n=306)$ and patients $(n=651)$, described as number (n) and percentage (\%) 


\begin{tabular}{|c|c|c|}
\hline Nursing staff & $\mathrm{n}$ & $\%$ \\
\hline \multicolumn{3}{|l|}{ Hospital } \\
\hline 1 & 98 & 32.0 \\
\hline 2 & 121 & 39.5 \\
\hline 3 & 87 & 28.4 \\
\hline \multicolumn{3}{|l|}{ Gender } \\
\hline female & 291 & 95.1 \\
\hline male & 15 & 4.9 \\
\hline \multicolumn{3}{|l|}{ Age (years) } \\
\hline$<30$ & 37 & 12.1 \\
\hline $30-39$ & 79 & 25.8 \\
\hline $40-49$ & 81 & 26.5 \\
\hline 50-59 & 88 & 28.8 \\
\hline $60-69$ & 21 & 6.9 \\
\hline \multicolumn{3}{|l|}{ Type of employment } \\
\hline Permanent & 254 & 83.0 \\
\hline Temporary & 52 & 17.0 \\
\hline \multicolumn{3}{|l|}{ Working Hours } \\
\hline Rotational; three-shift work & 187 & 61.1 \\
\hline Full day & 119 & 38.9 \\
\hline \multicolumn{3}{|l|}{ Type of contract } \\
\hline Full-time employment & 258 & 84.3 \\
\hline Short-term employment & 48 & 15.7 \\
\hline \multicolumn{3}{|l|}{ Work experience (years) } \\
\hline$<10$ & 80 & 26.1 \\
\hline 10-19 & 106 & 34.6 \\
\hline$\geq 20$ & 120 & 39.2 \\
\hline \multicolumn{3}{|l|}{ Patients } \\
\hline \multicolumn{3}{|l|}{ Hospital } \\
\hline 1 & 151 & 23.2 \\
\hline 2 & 364 & 55.9 \\
\hline 3 & 136 & 20.9 \\
\hline \multicolumn{3}{|l|}{ Gender } \\
\hline female & 388 & 60.0 \\
\hline male & 259 & 40.0 \\
\hline \multicolumn{3}{|l|}{ Age (years) } \\
\hline$<30$ & 78 & 12.5 \\
\hline 30-39 & 53 & 8.5 \\
\hline $40-49$ & 50 & 8.0 \\
\hline $50-59$ & 95 & 15.3 \\
\hline $60-69$ & 173 & 27.8 \\
\hline$\geq 70$ & 173 & 27.8 \\
\hline \multicolumn{3}{|l|}{$\begin{array}{l}\text { Hospital admission } \\
\text { of patients }\end{array}$} \\
\hline Planned & 421 & 58.1 \\
\hline Emergency & 224 & 30.96 \\
\hline
\end{tabular}

Table 2. Nurse managers' work activities $(n=29)$, nurses' job satisfaction $(n=306)$ and patient satisfaction $(\mathrm{n}=651)$ presented according to subscale, and described using mean score, standard deviation (SD), and Cronbach's alpha 


\begin{tabular}{|c|c|c|c|c|c|}
\hline Scale (number of items) & $\mathbf{n}$ & Mean & SD & $\alpha$ & scale \\
\hline \multicolumn{6}{|l|}{ Nurse managers' work activities } \\
\hline (NMWCQ) & 28 & 3.2875 & 88377 & 0.842 & \multirow{14}{*}{$\begin{array}{l}(1-6): \\
6=\text { daily } \\
5=\text { weekly } \\
4=\text { monthly } \\
3=2-4 \text { times a } \\
\text { year } \\
2=\text { annual } \\
1=\text { never }\end{array}$} \\
\hline Recruitment (5) & 28 & 4.6224 & .66350 & 0.767 & \\
\hline Organizing (7) & 28 & 3.4214 & .47559 & 0.738 & \\
\hline Work well-being (5) & 28 & 3.6429 & .77475 & 0.776 & \\
\hline Work atmosphere (3) & 28 & 3.8000 & .59129 & 0.478 & \\
\hline Communication (5) & 28 & 2.7450 & .99992 & 0.817 & \\
\hline Clinical nursing (9) & 28 & 4.0418 & .78712 & 0.916 & \\
\hline Development of the unit (12) & 28 & 3.4281 & .68550 & 0.769 & \\
\hline Personnel development (8) & 28 & 3.7232 & .80029 & 0.840 & \\
\hline Development of nursing (4) & 28 & 3.3010 & .78375 & 0.782 & \\
\hline Financial management (7) & 28 & 3.4464 & 62370 & 0.779 & \\
\hline Planning and evaluation of activities (6) & 28 & 3.9066 & .75205 & 0.835 & \\
\hline Collaboration (10) & 28 & 3.8869 & .49908 & 0.656 & \\
\hline \multicolumn{5}{|l|}{$\begin{array}{l}\text { Development with collaborating } \\
\text { partners }(6)\end{array}$} & \\
\hline \multicolumn{6}{|l|}{ Job satisfaction (KUHJSS) } \\
\hline Leadership (7) & 305 & 7.275 & 1.998 & 0.950 & \multirow{7}{*}{$\begin{array}{l}0-10: \\
0=\text { not satisfied } \\
\text { at all } \\
10=\text { completely } \\
\text { satisfied }\end{array}$} \\
\hline Requiring factors of work (8) & 303 & 6.340 & 1.648 & 0.843 & \\
\hline Motivating factors of the work (5) & 301 & 8.461 & 1.154 & 0.816 & \\
\hline Working welfare (4) & 304 & 7.992 & 1.296 & 0.723 & \\
\hline Participation in decision-making (4) & 303 & 6.492 & 1.889 & 0.815 & \\
\hline Sense of community (4) & 304 & 7.473 & 1.639 & 0.811 & \\
\hline Working environment (4) & 304 & 7.178 & 1.432 & 0.766 & \\
\hline \multicolumn{6}{|l|}{ Patient satisfaction (RHCS) } \\
\hline Professional practice (17) & 650 & 9.155 & 1.098 & 0.970 & \multirow{8}{*}{$\begin{array}{l}0-10: \\
0=\text { not satisfied } \\
\text { at all } \\
10=\text { completely } \\
\text { satisfied }\end{array}$} \\
\hline Information and participation in own & 650 & 8.813 & 1.387 & 0.946 & \\
\hline care (11) & 590 & 8.741 & 1.803 & 0.846 & \\
\hline Cognition of physical needs (4) & 642 & 8.512 & 1.775 & 0.881 & \\
\hline Human resources (3) & 621 & 8.356 & 1.917 & 0.786 & \\
\hline Pain and apprehension (4) & 645 & 9.153 & 1.162 & 0.916 & \\
\hline Interdisciplinary collaboration (3) & 644 & 8.929 & 1.479 & 0.894 & \\
\hline Outcomes variables (4) & & & & & \\
\hline
\end{tabular}

Abbreviations: $\mathrm{n}=$ number of participants, $\mathrm{SD}=$ standard deviation, $\alpha=$ Cronbach's Alpha

Table 3. The influences of nurse managers' work activities (NMWCQ), patient

satisfaction (RHCS) and medication errors on nurses' job satisfaction subareas at the unit ( $\mathrm{n}=$ 28) level 


\begin{tabular}{|c|c|c|}
\hline $\begin{array}{l}\text { Leadership (KUHJSS) } \\
p=.047^{*}\end{array}$ & $\begin{array}{l}\text { Requiring factors of work (KUHJSS) } \\
p<.001^{* * *}\end{array}$ & $\begin{array}{l}\text { Motivating factors of the } \\
\text { work (KUHJSS) } \\
p=.050^{*}\end{array}$ \\
\hline $\begin{array}{l}\text { Number of nurses } \\
\quad<40 \mathrm{~B}=.654 \\
\quad>40 \mathrm{~B}=0^{\mathrm{a}} \\
\text { Work well-being (NMWCQ) } \mathrm{B}= \\
-.413 \\
\text { Outcomes } \\
\text { variables (RHCS) } \mathrm{B}=.966 \\
\text { Medication errors } \mathrm{B}=.022\end{array}$ & $\begin{array}{l}\text { Development of nursing (NMWCQ) } \mathrm{B}= \\
-.623^{*} \\
\text { Cognition of physical needs (RHCS) } \mathrm{B}= \\
-.547 * * \\
\text { Outcomes variables (RHCS) } \mathrm{B}=.779 *\end{array}$ & $\begin{array}{l}\text { Communication (NMWCQ) } \mathrm{B}= \\
-.306^{*}\end{array}$ \\
\hline $\begin{array}{l}\text { Working } \\
\text { environment (KUHJSS) } \\
p=.002^{* *}\end{array}$ & $\begin{array}{l}\text { Working welfare (KUHJSS) } \\
p=.025^{*}\end{array}$ & $\begin{array}{l}\text { Total job satisfaction (KUHJSS) } \\
p=.044^{*}\end{array}$ \\
\hline $\begin{array}{l}\text { Hospital } \\
\qquad \begin{array}{l}1 \mathrm{~B}=.932 * * \\
2 \mathrm{~B}=.201 \\
3 \mathrm{~B}=0^{\mathrm{a}} \\
\text { Number of nurses } \\
\quad<40 \mathrm{~B}=-.410 \\
>40 \mathrm{~B}=0^{\mathrm{a}} \\
\text { Communication (NMWCQ) } \mathrm{B}= \\
-.457 *\end{array}\end{array}$ & $\begin{array}{l}\text { Cognition of physical needs (RHCS) } B= \\
-.239 *\end{array}$ & $\begin{array}{l}\text { Communication (NMWCQ) } \mathrm{B}= \\
-.301 \\
\text { Outcomes variables }(\mathrm{RHCS}) \mathrm{B}= \\
.403\end{array}$ \\
\hline
\end{tabular}

Significance: $*=p<0.05 ; * *=p<0.005 ; * * *=p<0.001$ Abbreviations: $\mathrm{B}=$ Unstandardized coefficients; NMWCQ= Nurse Managers' Work Content Questionnaire; KUHJSS= Kuopio University Hospital Job Satisfaction Scale; RHCS= Revised Humane Caring Scale

Table 4. The influences of nurse managers' work activities (NMWCQ), nurses' job satisfaction (KUHJSS) and medication errors on patient satisfaction (RHCS) subareas at the unit $(n=28)$ level 


\begin{tabular}{|c|c|c|c|}
\hline $\begin{array}{l}\text { Professional practice (RHCS) } \\
p=.004^{* *}\end{array}$ & $\begin{array}{l}\text { Information and } \\
\text { participation in own } \\
\text { care (RHCS) } \\
p=.007^{* *}\end{array}$ & $\begin{array}{l}\text { Cognition of physical needs } \\
\text { (RHCS) } \\
p=.003^{* *}\end{array}$ & $\begin{array}{l}\text { Human resources } \\
\text { (RHCS) } \\
p=.028^{*}\end{array}$ \\
\hline $\begin{array}{l}\text { Organizing (NMWCQ) } \mathrm{B}= \\
-.124 \\
\text { Clinical nursing (NMWCQ) } \mathrm{B}= \\
-.178^{*} \\
\text { Leadership (KUHJSS) } \mathrm{B}= \\
-.114^{*}\end{array}$ & $\begin{array}{l}\text { Organizing (NMWCQ) } \\
\mathrm{B}=-.201 \\
\text { Medication errors } \mathrm{B}= \\
-.011^{* *}\end{array}$ & $\begin{array}{l}\text { Development of nursing } \\
\text { (NMWCQ) } B=-.782^{* *} \\
\text { Requiring factors of } \\
\text { work (KUHJSS) } B=-.543^{* *}\end{array}$ & $\begin{array}{l}\text { Financial management } \\
\text { (NMWCQ) } B=-.273^{*} \\
\text { Medication errors } B= \\
-.014^{*}\end{array}$ \\
\hline $\begin{array}{l}\text { Pain and apprehension } \\
\text { (RHCS) } \\
p=.005^{* *}\end{array}$ & $\begin{array}{l}\text { Interdisciplinary } \\
\text { collaboration (RHCS) } \\
p=.002^{* *}\end{array}$ & $\begin{array}{l}\text { Outcomes variables (RHCS) } \\
p=.002^{* *}\end{array}$ & $\begin{array}{l}\text { Total patient } \\
\text { satisfaction (RHCS) } \\
p<.001^{* *}\end{array}$ \\
\hline $\begin{array}{l}\text { Communication (NMWCQ) } \mathrm{B}= \\
.324^{*} \\
\text { Development of nursing } \\
\text { (NMWCQ) } \mathrm{B}=-.327 \\
\text { Working welfare (KUHJSS) } \\
\mathrm{B}=-.420 \\
\text { Medication errors } \mathrm{B}=-.011^{*}\end{array}$ & $\begin{array}{l}\text { Work well-being } \\
\text { (NMWCQ) } B=-.171 * \\
\text { Medication errors } B= \\
-.005 * *\end{array}$ & $\begin{array}{l}\text { Leadership (KUHJSS) } \mathrm{B}= \\
.132^{*} \\
\text { Medication errors } \mathrm{B}= \\
-.011^{* *}\end{array}$ & $\begin{array}{l}\text { Work well-being } \\
(\text { NMWCQ) } \mathrm{B}=-.217 * * \\
\text { Working } \\
\text { welfare (KUHJSS) } \mathrm{B}= \\
-.356^{* *} \\
\text { Medication errors } \mathrm{B}= \\
-.006^{* *}\end{array}$ \\
\hline
\end{tabular}

Significance: $*=p<0.05 ; * *=p<0.005 ; * * *=p<0.001$

Abbreviations: $B=$ Unstandardized coefficients; NMWCQ= Nurse Managers' Work Content Questionnaire; KUHJSS= Kuopio University Hospital Job Satisfaction Scale; RHCS= Revised Humane Caring Scale

Table 5. The influence of hospital, nurse managers' work activities (NMWCQ), and patient satisfaction (RHCS) on medication errors at the unit $(n=28)$ level

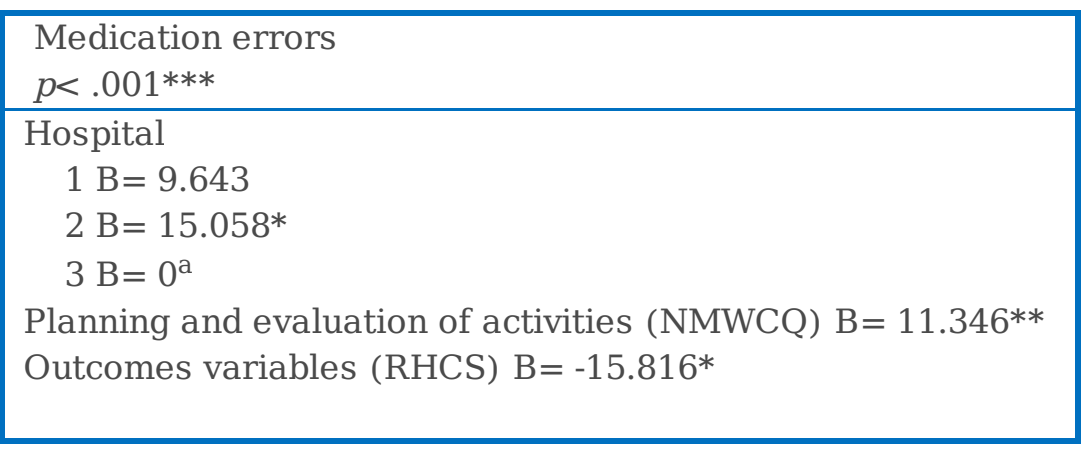

Significance: $*=p<0.05 ; * *=p<0.005 ; * * *=p<0.001$

Abbreviations:

$\mathrm{B}=$ Unstandardized coefficients; NMWCQ= Nurse Managers' Work Content Questionnaire; KUHJSS = Kuopio University Hospital Job Satisfaction Scale; RHCS= Revised Humane Caring Scale

\section{Supplementary Files}

This is a list of supplementary files associated with this preprint. Click to download.

- Additionalfile1.NMWCQ.docx 
- Additionalfile2.KUHJSS.docx

- Additionalfile3.RHCS.docx

- STROBEchecklistcrosssectional.docx 